\title{
Evaluation of the role of CD47 in sickle cell disease
}

\author{
Basmah Eldakhakhny ${ }^{1} \cdot$ Hadeel Al Sadoun ${ }^{2} \cdot$ Nehal Bin Taleb $^{3} \cdot$ Dunya Ahmed Nori ${ }^{3} \cdot$ Nawal Helmi $^{4}$. \\ Iffat Mirza Ahmed ${ }^{5}$. Muhammed A. Bakhrebah ${ }^{6}$. Wesam H. Abdulaal ${ }^{3}$
}

Received: 7 July 2020 / Accepted: 8 December 2020 / Published online: 2 January 2021

(C) The Author(s) 2021

\begin{abstract}
CD47 is a self-marker expressed on the surface of RBCs and work to prevent the process of phagocytosis. SIRP $\alpha$ is the ligand of CD47 that is expressed on the surface of phagocytic cells, such as macrophages, to control the removal of dead/diseased cells. This study aimed to examine the expression of CD47 on RBCs and SIRP $\alpha$ on PBMC cells in SCD patients and the apoptosis of SCD RBCs. We also measured the levels of pro-inflammatory cytokines in SCD patients and correlated it with the cell surface marker expression of CD47 and SIRP $\alpha$ to determine whether CD47 and/or $\operatorname{SIRP} \alpha$ played a role in promoting the proinflammatory phenotype in SCD. Whole blood samples were drawn from SCD patients, and healthy control and PBMC were isolated and stained with $\operatorname{SIRP} \alpha$. Change in $\mathrm{CD} 47$, apoptosis by annexin V marker, and pro-inflammatory cytokines were measured and correlation among these variants was determined. The expression of CD47 was significantly decreased and the apoptosis was increased in RBCs of SCD patients. A higher level of pro-inflammatory cytokines, IL- 6 and IL-1 $\beta$, was found in SCD patients and IL- $1 \beta$ was found to be inversely correlated with SIRP $\alpha$ expression. Our data showed that CD 47 of erythrocytes of SCD samples is reduced and that the apoptosis is increased in those patients. Based on the role of CD47, we suggest that increased apoptosis in SCD would be impacted by the reduced level of CD47. An inverse relationship was found between SIRP $\alpha$ marker on PBMC and the increased production of pro-inflammatory cytokines in SCD.
\end{abstract}

Keywords CD47 $\cdot$ Sickle cell anemia $\cdot$ Sickle cell disease $\cdot$ Signal regulatory protein alpha $\cdot \operatorname{SIRP} \alpha$

Basmah Eldakhakhny and Hadeel Al Sadoun have equal contribution as first authors.

Hadeel Al Sadoun

hsadounkau.ed.sa@kau.edu.sa

1 Department of Clinical Biochemistry, Faculty of Medicine, King Abdulaziz University, Jeddah, Saudi Arabia

2 Department of Medical Laboratory Technology, Faculty of Applied Medical Sciences, Stem Cell Unit, King Fahd Medical Research Center, King Abdulaziz University, Jeddah, Saudi Arabia

3 Department of Biochemistry, Faculty of Sciences, King Abdulaziz University, Jeddah, Saudi Arabia

4 Department of Biochemistry, Faculty of Sciences, University of Jeddah, Jeddah, Saudi Arabia

5 Department of Oral \& Maxillofacial Surgery, Vision Colleges for Dentistry and Nursing, Jeddah, Saudi Arabia

6 Life Science and Environment Research Institute, King Abdulaziz City for Science and Technology (KACST), Riyadh, Saudi Arabia

\section{Introduction}

Sickle cell disease (SCD) is a hereditary disorder affecting the RBCs' morphology changing it from biconcave to sickle-shaped that is caused by the mutation in the beta-globin gene which forms the hemoglobin $\mathrm{S}(\mathrm{Hb} \mathrm{S})$ instead of hemoglobin $\mathrm{A}(\mathrm{Hb}$ A). SCD patients suffer from chronic hemolytic anemia due to accelerated intravascular or extravascular hemolysis in which phagocytes, including monocytes and macrophages, play an important role [1]. This leads to shortening of the life span of RBCs from 120 days to 10-20 days. In addition to clearing the tissues from infectious agents, macrophages scavenge dead and aged cells that have completed their life span by phagocytosis [2].

Physiological removal of RBCs at the end of their life span is also mediated by extravascular hemolysis. The same applies to the sickled cells that must be cleared out from the blood vessels to prevent vaso-occlusive disease while leaving healthy cells protected from macrophage attack [2]. It is still not clear how macrophages decide which RBCs must be removed and which can be preserved $[3,4]$. Many studies proposed that the RBCs clearance can be associated with changes in cell surface markers in RBCs and that conformational changes to these markers are 
responsible for the macrophage's careful selection [5]. Also, inhibitory receptors on the surface of macrophages help in the recognition of those markers by macrophages [6]. Signal regulatory protein alpha (SIRP $\alpha$ ) is an immunoglobulin superfamily protein that acts as an immunoreceptor. It is expressed on the macrophages and works as an inhibitor to phagocytosis when it comes in contact with CD47 expressing cells $[5,7]$.

CD47 is a member of the immunoglobulin superfamily protein and acts as a self-marker, expressed on mammalian cells, including RBCs, which prevents phagocytosis when coupled with SIRP $\alpha$ (on macrophages). Under this condition, CD47 functions as a "do not eat me" signal [7, 8]. CD47 is also found on the surface of tumor cells [9] and acts as a ligand for SIRP $\alpha$ [10-12]. Hence, CD47 and SIRP $\alpha$ play a critical role in regulating phagocytosis [7]. This study looks at the role of the inhibitory receptor (SIRP $\alpha)$ and its ligand CD47 in the regulation of phagocytosis in SCD.

Previous studies proposed that conformational changes occurred to the RBC cell surface marker, CD47, where phagocytosis of apoptotic cells is required, such during aging. These conformational changes enabled the CD47 to be recognized by phagocytic cells as an "eat me" instead of a "do not eat me" signal $[5,7]$. This suggests that CD47-SIRP $\alpha$ interaction can promote phagocytosis as well as prevent it.

Phagocytosis of sickled RBCs plays a role in the initiation of inflammatory symptoms such as fever, pain, and swelling by releasing cytokines [13]. Uncontrolled inflammation may lead to sickle cell crisis, which is a major problem for patients with SCD [13].

In this study, we looked at the effect of SCD on CD47 cell surface marker expression on RBCs and SIRP $\alpha$ surface marker expression on phagocytic cells and how each marker is correlated to the process of apoptosis in SCD. We then compare the level of the inflammatory cytokine between healthy and SCD patients and whether they correlated with changes in $\operatorname{SIRP} \alpha$ and CD47.

\section{Materials and methods}

Whole blood samples were obtained from 16 homozygous SCD patients and 16 healthy volunteers. All SCD patients were stable not in active crisis. The sample size was calculated based on Kelsey's method [14] with a total sample size of 32 divided equally between controls and cases. Ethical approval was obtained following the guidelines of the Ethics Committee at King Abdulaziz University Hospital, and all donors signed an informed consent form (Reference No. 611-19). Six milliliters of whole blood samples was collected from SCD patients and healthy volunteers and divided into two tubes. Three milliliters was added to a heparin anticoagulated vacutainer tube for cell separation and the remaining was in a serum separating tube (free of anticoagulant) to collect serum. Serum was prepared by centrifugation of coagulated blood at $1500 \times \mathrm{g}$ for $10 \mathrm{~min}$ and stored at $-80{ }^{\circ} \mathrm{C}$ for subsequent cytokine analysis.

\section{Isolation of peripheral blood mononuclear cells}

An equal volume of phosphate-buffered saline (PBS) with $2 \mathrm{ml}$ of heparinized blood was mixed carefully and was added onto the surface of $4 \mathrm{ml}$ of Histopaque 1077 (density: $1.077 \mathrm{~g}$ / ml; SIGMA). Using a $15-\mathrm{ml}$ conical tube, the mixture was centrifuged at $400 \times g$ for $30 \mathrm{~min}$. The buffer coat containing peripheral blood mononuclear cells (PBMCs) was collected and transferred into a 15-ml conical tube and washed twice in PBS+EDTA and pelleted by centrifugation at $300 \times g$ for $10 \mathrm{~min}$. The number of PBMCs was counted by a hemocytometer and cell viability was determined using trypan blue.

\section{Measurement of SIRPa surface expression on PBMCs using flow cytometry}

For flow cytometry analysis, $3 \times 10^{5}$ cells/ml were resuspended in FACS buffer (PBS supplemented with 1\% FBS and $0.09 \%$ sodium azide $\left.\left(\mathrm{N}_{\mathrm{a}} \mathrm{N}_{3}\right)\right)$. At first, PBMCs containing monocytes and macrophages were labelled with $1.5 \mu \mathrm{l}$ of $\mathrm{Fc}$ receptor, Human TruStain FcX (BioLegend), and incubated at room temperature for $5 \mathrm{~min}$ and protected from light. Cells were then stained with $3 \mu \mathrm{l}$ of the PE anti-human CD172a (SIRP $\alpha)$ antibody (BioLegend) and incubated in the dark for $30 \mathrm{~min}$ on ice. A tube with no antibody was used as a negative control for flow analysis. Flow cytometry was performed using the BD FACSAria III (BD Biosciences) flow cytometer and FACSDIVA software.

\section{Isolation and counting of RBCs}

Whole blood was mixed with an equal volume of PBS and was carefully added into the surface of $4 \mathrm{ml}$ of Histopaque 1077 (density: $1.077 \mathrm{~g} / \mathrm{ml}$; SIGMA) in a $15-\mathrm{ml}$ conical tube and was subject to centrifugation at $400 \times g$ for $30 \mathrm{~min}$. The supernatant was removed and RBCs were sedimented. One milliliter of RBCs was washed with an equal volume of PBS and was subject to centrifugation at $300 \times g$ for $5 \mathrm{~min}$. The total number of red blood cells was counted by a hemocytometer using 1:200 dilution with PBS.

\section{Measurement of CD47 surface expression on RBCs using flow cytometry}

Isolated RBCs were washed and diluted with FACS buffer and $1 \times 10^{6}$ cells $/ \mathrm{ml}$ were used per assay. Cells were stained with $3 \mu \mathrm{l}$ of the Pacific BlueTM anti-human CD47 antibody (BioLegend). Flow cytometry analysis performed using the BD FACSAria III flow cytometer and FACS DIVA software. 
Measurement of apoptosis of RBCs using annexin VFITC apoptosis staining/detection kit

Apoptosis of RBCs was determined using an annexin V apoptosis kit (Abcam) following the manufacturer's instruction. In brief, $1 \times 10^{5}$ cells $/ \mathrm{ml}$ were suspended into annexin $\mathrm{V}$ binding buffer and incubated with annexin V-FITC and propidium iodide. Samples were analyzed within $15 \mathrm{~min}$, and analyses were performed using the BD FACSAria III flow cytometer and FACSDIVA software.

\section{Measurement of cytokine concentration}

TNF- $\alpha$, IL-1 $\beta$, IL- 6 , and IL-12 production were determined using Invitrogen human-specific enzyme-linked immunosorbent assay (ELISA) kits (TermoFischer). Cytokine measurement was made according to the manufacturer's instructions. Briefly, standards and blank samples were added in 96 ELISA microwell plates coated with a monoclonal antibody that corresponded to each of the cytokines and incubated at room temperature for $2 \mathrm{~h}$ with Biotin-Conjugate. The 96-well plates were then washed four times with wash buffer and incubated at room temperature for $1 \mathrm{~h}$ with Streptavidin-HRP. The plates were then washed four times with wash buffer and TMB Substrate Solution was added and incubated for $10 \mathrm{~min}$ at room temperature. After the incubation, Stop Solution was added to all microwell plates. The plate was read on Synergy ${ }^{\mathrm{TM}}$ HT microplate reader (BioTek Instruments, Winooski, USA) using Gen5 ${ }^{\mathrm{TM}}$ software.

\section{Statistical analyses}

All statistical analyses and graphs were carried out in GraphPad Prism 8 (version 8.2.1(441), GraphPad Software, Inc.). Student's unpaired two-tailed $t$ test was used to define the differences between groups in means. Data are shown as means \pm SEM.

$p$ value $<0.05$ was considered significant and the significance levels were set to $* p<0.05, * * p<0.01$, and $* * * p<0.001$. Correlations among the parameters were determined by Pearson's correlation coefficient $(r)$.

\section{Results}

\section{CD47 but not SIRPa cell surface marker is reduced in sickle cell patients}

Flow cytometry analysis was made on blood samples (RBCs and PBMCs) collected from sickle cell disease patients $n=16$ and healthy individuals (control) $n=16$. The percentage of CD47 expression in SCD patients' RBCs was $77 \%$, whereas that on RBCs of healthy individuals was $87 \%$. The change in the CD47 cell surface marker expression in SCD patients' samples was significant compared to healthy subjects $(p<0.05)$ (Fig. 1a, b).

Phagocytes were isolated from the blood of healthy controls and SCD patients and the expression of SIRP $\alpha$ was determined. There was no observable change in the level of SIRP $\alpha$ expression on phagocytic cells extracted from sickled sample comparing to healthy control (Fig. 1c, d).

\section{Sickled RBCs are more apoptotic}

Using annexin V staining that can determine the apoptosis of human cells, we found that the percentage of apoptosis in normal RBCs was no more than $1 \%$, while sickled RBC apoptosis increased up to $5 \%$. The difference between sickled and normal cell apoptosis was statistically significant $(p<0.001)$ (Fig. 2a, b).

\section{Identification of cytokines}

The level of the pro-inflammatory cytokines IL-1 $\beta$, IL-6, IL12 , and TNF- $\alpha$ were measured in serum using ELISA. Among all the cytokines tested, we observed that the IL-1 $\beta$ production was significantly increased in SCD patients at $12.68 \mathrm{pg} / \mathrm{ml}$ as compared to healthy subjects at $7.24 \mathrm{pg} / \mathrm{ml}$, showing a statistical significance $(p<0.03)$ (Fig. 3). Similarly, the mean serum of IL- 6 production was $9.58 \mathrm{pg} / \mathrm{ml}$ in SCD patients, and $4.08 \mathrm{pg} / \mathrm{ml}$ in healthy subjects, which showed a significant difference $(p<0.0001)$. On the other hand, the difference in TNF- $\alpha$ and IL-12 production between SCD serum and healthy volunteers was not significant.

\section{Correlation between CD47, SIRPa cell surface markers, apoptosis of RBCs, and cytokine production from the serum of SCD patients}

A negative correlation was found between serum level of IL-6 and CD47 expression as well as between IL-1 $\beta$ and SIRP $\alpha$ expression.

A positive correlation was found between serum level of IL- 6 and the percentage of apoptosis as well as between IL-1 $\beta$ and serum TNF- $\alpha$ (Fig. 4). Correlation between cytokine production and CD47 expression, SIRP $\alpha$ expression, and the apoptosis of RBCs were measured (supplementary table 1) in SCD patients and healthy subjects. Pearson's correlation calculation demonstrated a significant (negative) correlation between both of IL- $1 \beta$ and TNF- $\alpha$ levels with SIRP $\alpha$ expression in the patient's group $(p<0.01)$. Among the healthy group, IL-1 $\beta$ levels were negatively correlated with CD47 expression $(p<0.001)$. Altogether, the correlation data support the association between CD47 expression and clearance of RBCs by phagocytes in SCD and healthy subjects. SIRP $\alpha$ did not show the same correlation with apoptosis of RBCs. 
$\boldsymbol{a}$

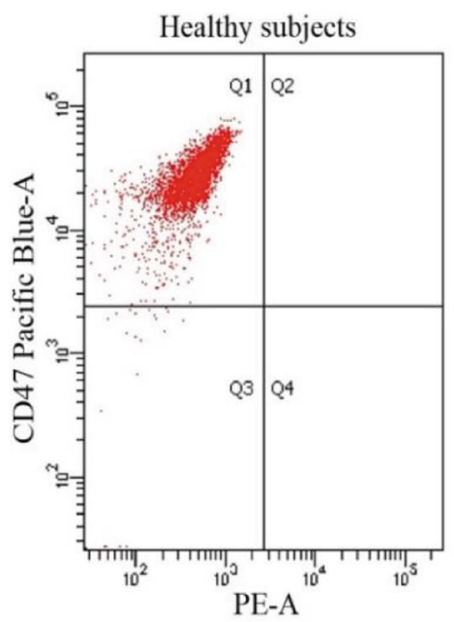

c

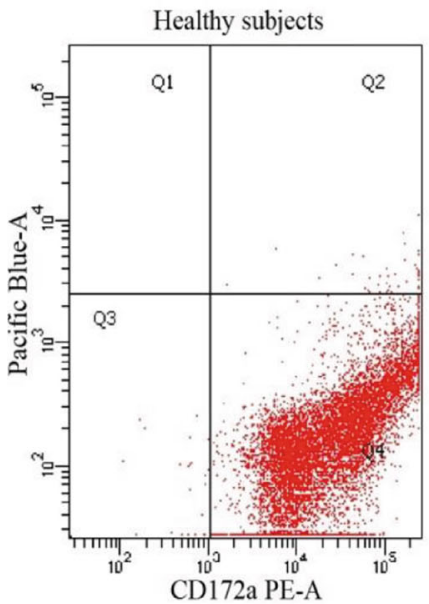

b
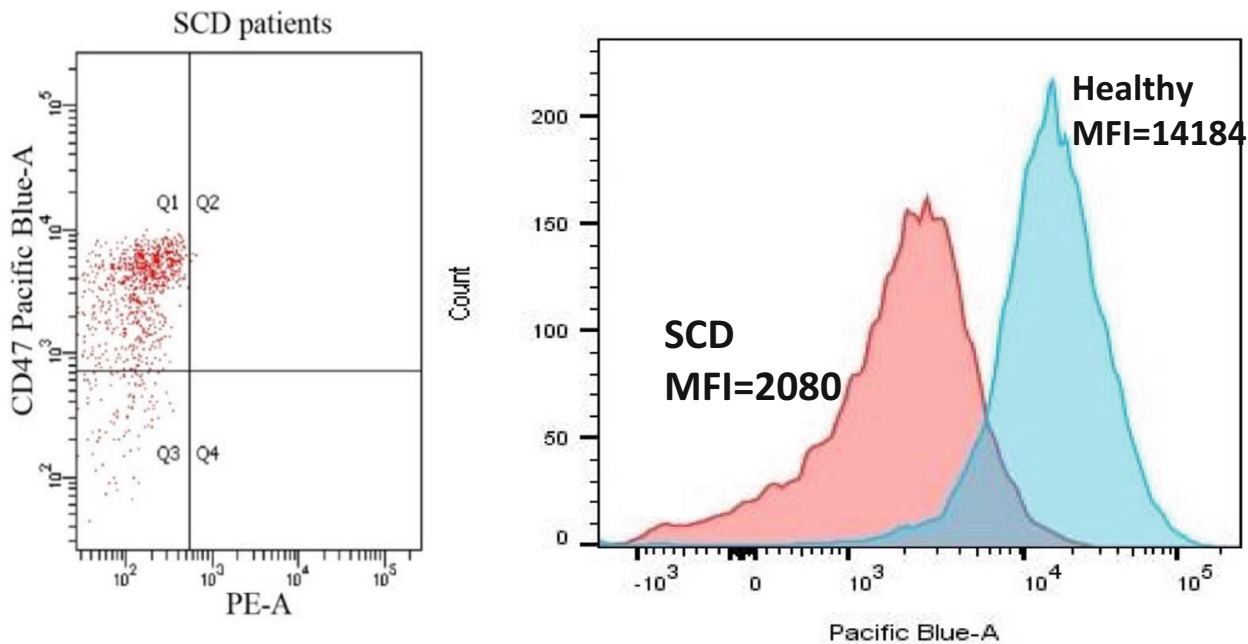

d

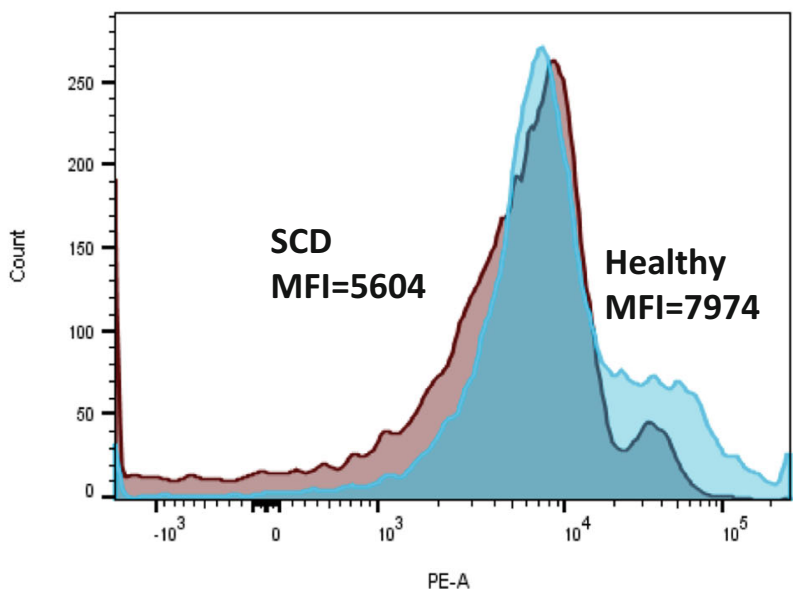

Representative flow cytometry dot plot results of $\operatorname{SIRP} \alpha / \mathrm{CD} 172 \mathrm{a}$ in healthy phagocytic cell (left) and phagocytic cells from sickled patient (right). d Representative flow cytometry histogram showing MFI of SIRP $\alpha$ in phagocytic cell from SCD patients (red shading) compared with phagocytic cells from healthy subjects (turquoise shading)

conditions particularly when apoptosis is involved in the process. An example of the involvement of these two surface markers is the study that Jaiswal and colleagues found in 2009, where they identified an increase in the expression of CD47 on the surface of normal hematopoietic cells once they migrate into the circulation as a form of protection from phagocytosis, and that leukemic cells tend to increase their pathogenicity by increasing the level of CD47 surface marker expression as a form of escaping immune phagocytic process [9]. The same was evident in ovarian cancer patients, whereby the research group categorized cancer patients into $\mathrm{CD} 47^{\mathrm{lo}}$ patients as good responders who responded well to adjuvant therapy and the $\mathrm{CD} 47^{\mathrm{hi}}$ patients as poor responders that had means of escaping the immune response [16]. In line with these studies, blocking the CD47 antigens by immunotherapeutic anti-CD47 
a

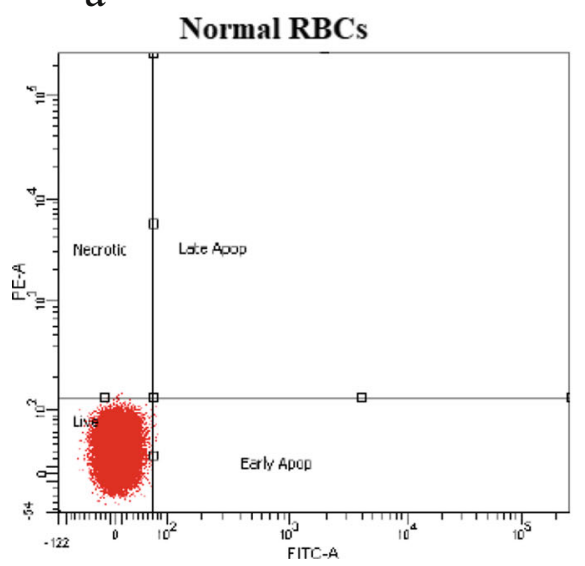

Sickled RBCs

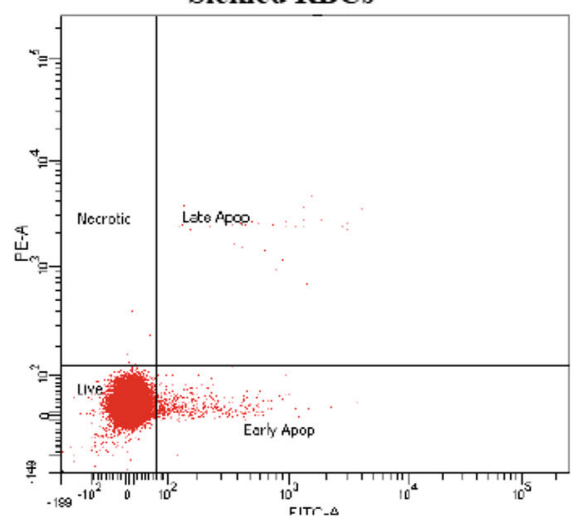

b

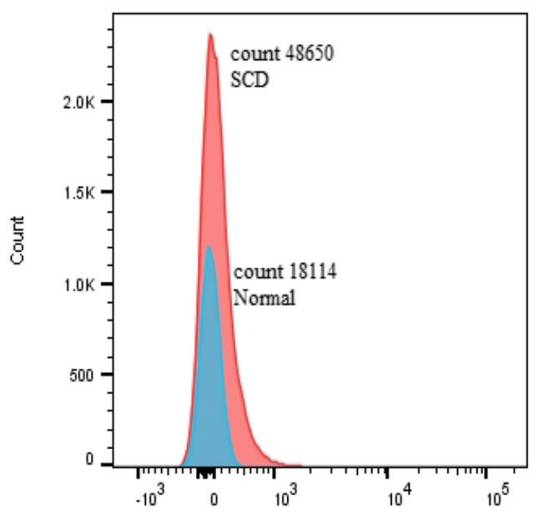

Fig. 2 Apoptosis of RBCs using Annexin V apoptosis kit. a Representative flow cytometric dot plot for healthy RBCs (left) and sickled RBC (right) showing positive signs of apoptosis in sickled RBC. b
Representative histogram showing the difference in MFI of apoptosis marker between sickled RBCs (red shading) and healthy RBCs (turquoise shading). ( $p$ value $<0.0001$ )

antibodies in small cell lung carcinoma mediated the phagocytosis in cell culture and markedly inhibited the tumor lung cancer [17]. Therapeutic interventions such as blockage of CD47$\operatorname{SIRP} \alpha$ interaction or targeting the FC receptor can stimulate phagocytosis of cancer cells in vitro and work as a strategy to prevent the growth of cancer cells in vivo [18, 19]. Monoclonal anti-CD47 antibodies, namely Hu5F9-G4, are currently in clinical trials to test their efficacy in treating hematological malignancies or solid tumors by interfering with $\operatorname{CD} 47-\operatorname{SIRP} \alpha$ binding, disrupting their anti-phagocytic activity leading to phagocytosis of cancer cell [20-22].

Fig. 3 Pro-inflammatory cytokine production in serum of SCD patients and healthy subjects. Production of IL-1 $\beta$ (a), IL12 (b), IL6 (c), and TNF $\alpha$ (d) in healthy control (black bar) and sickled patient's sample (gray bar). $* p<0.05, * * * * p<0.0005$ a

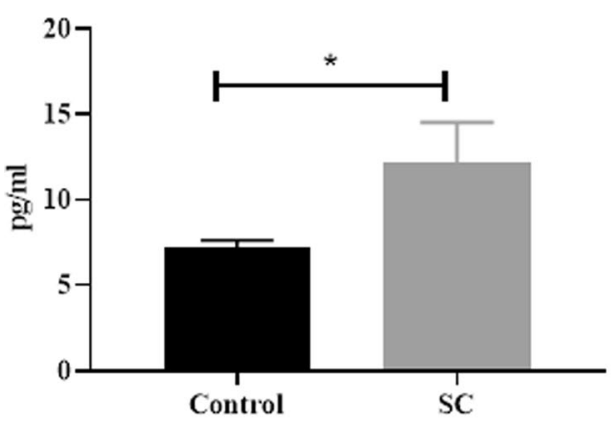

IL6

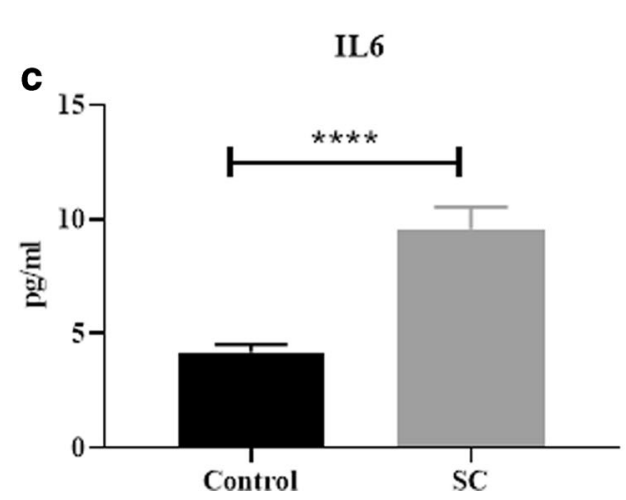

In the current study, we measured CD47 expression level in normal and sickled erythrocytes and found that SCD patients' RBC showed lower expression of their self-antigen CD47. The importance of CD47 is not only in cell survival and protection, but it is also a member of $\mathrm{Rh}$ complex on the surface of RBCs that complex with surface protein such as $\mathrm{Rh}$, Band3, and GPA [23]. The impact of ABO grouping and particularly the Rh phenotype on CD47 cannot be neglected. On the surface of RBCs, CD47 complexes with a member of $\mathrm{Rh}$ group protein (RhAG and $\mathrm{RhD}$ ) [23]. This raises the question of whether the reduced CD47 we found in SCD is b $\quad$ IL12

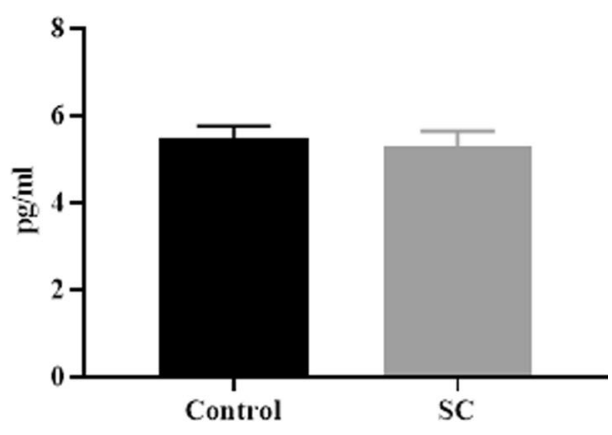

TNF $\alpha$

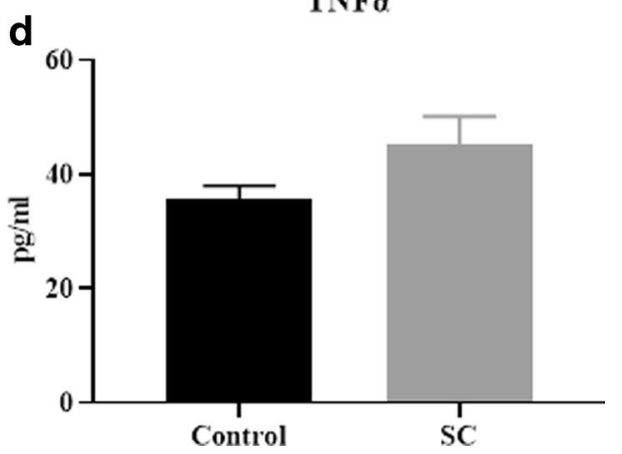


Fig. 4 Correlation between the level of IL- $1 \beta$ and IL- 6 with the expression of CD47 SIRP $\alpha$ and $\%$ of apoptosis in SCD patients. Data presented as linear regression (mean and error); $p$ value presented as $* p<0.05$, $* * p<0.01, * * * p<0.001$, $* * * * p<0.0001$
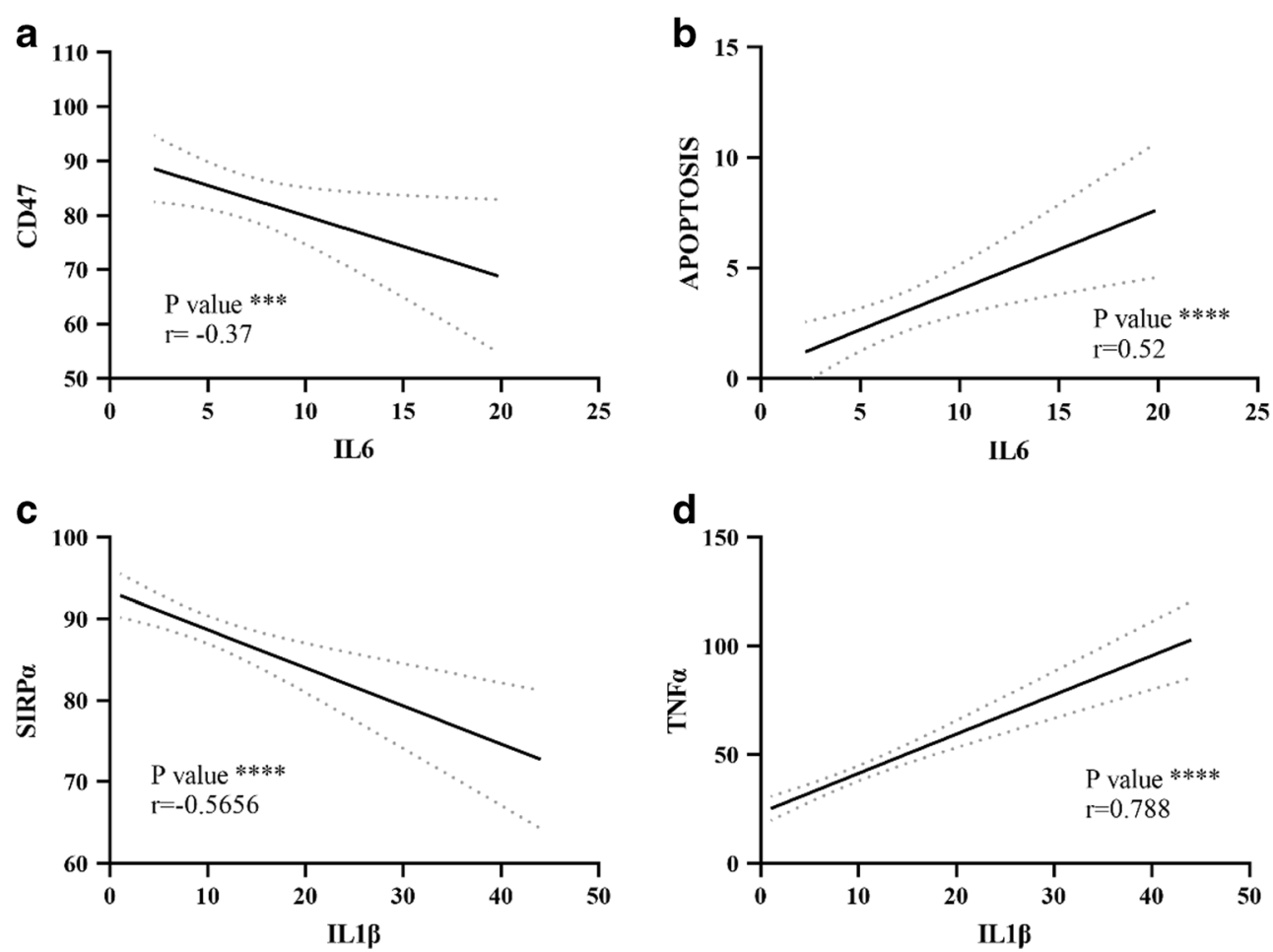

impacted by changes in their Rh phenotype. It would be interesting to look at the Rh group of our selected patient population to roll out the possibility that the changes we observed in CD47 expression were impacted by different Rh status.

CD47 is reduced with aging, and conformational changes occur to this protein or its ligand $\operatorname{SIRP} \alpha$ to support $\mathrm{RBC}$ recognition and clearance by macrophages [24]. An example of that is the old murine RBCs that showed $30 \%$ less expression of CD47 than in younger ones. The reduction in CD47 in SCD RBCs in our data is inversely proportional to apoptosis of erythrocytes as evident by the increased annexin $\mathrm{V}$ marker. This supports the role of CD47 and their ligand SIRP $\alpha$ as a regulator of cell survival and death [25].

Burger et al. [5], on the other hand, provided evidence that suggests that in senescent RBCs, the expression level of surface CD47 is not reduced compared to normal RBCs, but instead changed their structure. This conformational change occurs during the aging of RBCs as a result of oxidative stress, after which thrombospondin (TSP-1) binds to CD47 creates a new binding site for $\operatorname{SIRP} \alpha$. Consequently, the "do not eat me" signal from CD47 marker can be recognized as an "eat me" signal [5]. In support of conformational changes on CD47, a study showed that cell apoptosis is not associated with CD47 reduction but with the binding capacity of CD47 to $\operatorname{SIRP} \alpha$, which is affected by the alteration in the distribution pattern of CD47 during apoptosis. Whereas CD47 clustered on the cell surface in lipid rafts on nonapoptotic cells, it is spread on the cell surface in the plasma membrane when apoptosis occurs. This change of CD47 results in loss of the high binding avidity to $\operatorname{SIRP} \alpha$ [7]. Changes in RBCs' membrane and their rigidity are one factor that plays a role in impacting CD47 on RBCs. Sosale and colleagues [26] found that rigid RBCs that still maintain their biconcave shape show accelerated phagocytosis compared to flexible cells. This is due to active myosine II that overrides the self-signals from CD47 [26]. Our study supports that in SCD that changes the morphology and rigidity of RBCs, CD47 self-antigen is reduced, which may support that myosin II overrides the inhibitory signals from CD47 and accelerate the phagocytosis by macrophage, which forms the basis of extravascular hemolysis of hemolytic anemia. The fact that CD47 can complex with fixability protein such as ankyrin, protein 4.2 , and band 3 may have played a role in this process and would be interesting to further investigate their involvement. In regard to the apoptosis observed in sickled patient compared to healthy cells, one would suggest a functional assay looking at the protein-protein interaction between SIRP $\alpha$-CD47 and/or anti-CD47 immunotherapeutic antibody to determine whether the cause for increased destruction of sickled erythrocytes is due to the binding affinity between the two proteins or due to reduced CD47 on the surface of erythrocytes.

In the current study, the receptor of $\operatorname{CD} 47, \operatorname{SIRP} \alpha$, was measured to detect any changes in the expression of $\operatorname{SIRP} \alpha$ in PBMC in healthy and sickle cell anemia samples. Comparative analyses of $\operatorname{SIRP} \alpha$ expression level in healthy individuals versus sickle cell anemia patients showed no significant changes in this marker and proposed that the changes occurred in apoptosis in sickled 
RBCs might not be related to changes in SIRP $\alpha$ levels in those patients. The increase in the apoptosis marker annexin V in SCD erythrocytes that we observed in our study could be a natural consequence of decreased CD47 in SCD comparing to healthy cells.

Our correlation data shows that there was no strong correlation between the apoptosis of the RBCs and the expression of $\operatorname{SIRP} \alpha$ on macrophages of sickle cell anemia.

Another aspect of this study is the inflammation in SCD patients. Sickling can lead to the continuous activation of granulocytes, monocytes, and platelets as a result of hemolysis and vaso-occlusion [27]. Therefore, the impact of SCD on inflammatory cytokines was investigated in serum samples isolated from patients with SCD in a steady state. Our results showed increased pro-inflammatory cytokine secretion from SCD patient's serum, particularly in IL- $1 \beta$, IL- 6 , and TNF- $\alpha$ in comparison to healthy controls and normal ranges, thus supporting the inflammatory nature of the disease. In our case, the inflammatory cytokines were elevated even in the absence of a hemolytic crisis. Previous studies showed that inflammatory markers could be further increased when samples were extracted during the active phases of the crisis [28, 29]. Increased inflammatory cytokines in isolated monocytes from SCD patients explained by the fact that RBCs hemolysis releases heme into the circulation, which in turn activates endothelial cells that can stimulate monocytes to release proinflammatory factors in response to Toll-like receptor 4 (TLR4) and placental growth factor (PIGF) (reviewed in [30]). The above results are suggestive of the proinflammatory nature of myeloid cells, even in the absence of a hemolytic crisis that can be complicated by inflammatory responses during the painful crisis attack that was explained by neurogenic inflammation and neuropathy (reviewed in [30]). Inflammatory pain is caused by increased levels of COX-2, IL-6, and TLR4 in the spinal cord [31]. Thus, targeting inflammatory mediators can be helpful for pain management.

We, therefore, investigated whether there is any form of correlation with what we observed with anti-phagocytosis marker expression CD47 and their receptor, $\operatorname{SIRP} \alpha$, and the increased level of IL-6, IL-1 $\beta$, and TNF- $\alpha$ observed in sickle cell anemia. Interestingly, our study indicated a moderate negative correlation between the IL- 6 cytokine and CD47 levels. However, IL$1 \beta$ cytokine production was negatively correlated with the receptor of CD47 and the SIRP $\alpha$ expression on monocytes. Altogether, the data here suggest that CD47 and SIRP $\alpha$ could be a negative regulator of inflammation. Unlike our findings, Kong and colleagues found that in LPS-stimulated macrophages, SIRP $\alpha$ leads to increased production of proinflammatory cytokines, including TNF- $\alpha$ and IL- 6 via activation of the mitogen-activated protein kinases (MAPKs) and nuclear factor $\kappa B(N F-k B)$ pathways [32]. This could be explained by the fact that in vitro stimulation of the cells works in a different mechanism about $\operatorname{SIRP} \alpha$ and inflammatory cytokines. Therefore, the impact of SIRP $\alpha$ on the inflammation of SCD must be well studied before any utilization as a potential target to control the inflammatory response in sickle cell anemia.

This study is limited by the fact that it reports CD47 expression in SCD in which Rh phenotype is not determined. A better conclusion can be made if the Rh status of the patient and control groups is determined and not changed among the two populations. Thus, we can rule out the possibility that the changes we observed in CD47 expression were impacted by the Rh status.

\section{Conclusion}

This study revealed decreased CD47 expression and increased apoptosis of RBCs in SCD patients. However, the CD47 ligand SIRP $\alpha$ expressed on monocytes was not affected by SCD. Cytokine analysis and Pearson's correlation showed an inverse relationship between $\operatorname{CD} 47, \operatorname{SIRP} \alpha$, and inflammatory cytokine production. Further studies would help in identifying the role of blocking SIRP $\alpha$ and the response in inflammatory markers and how $\mathrm{CD} 47$-SIRP $\alpha$ co-immunoprecipitation may impact the process of apoptosis and the severity of hemolytic anemia in those patients.

Understanding cytokine production and secretion is important in controlling inflammatory response and management of neuropathic pain in sickle cell disease during crises and may help in the development of effective therapies to control SCD complications.

Supplementary Information The online version contains supplementary material available at https://doi.org/10.1007/s12308-020-00433-5.

Acknowledgments The authors would like to thank King Abdulaziz City for Science and Technology (KACST) for technical support.

Funding This research was funded by the Deanship of Scientific Research (DSR) at King Abdulaziz University, Jeddah, Saudi Arabia (project no. DF-429-248-1441).

\section{Compliance with ethical standards}

Conflict of interest The authors declare that they have no conflict of interest.

Open Access This article is licensed under a Creative Commons Attribution 4.0 International License, which permits use, sharing, adaptation, distribution and reproduction in any medium or format, as long as you give appropriate credit to the original author(s) and the source, provide a link to the Creative Commons licence, and indicate if changes were made. The images or other third party material in this article are included in the article's Creative Commons licence, unless indicated otherwise in a credit line to the material. If material is not included in the article's Creative Commons licence and your intended use is not permitted by statutory regulation or exceeds the permitted use, you will need to obtain permission directly from the copyright holder. To view a copy of this licence, visit http://creativecommons.org/licenses/by/4.0/. 


\section{References}

1. Brousse V, Buffet P, Rees D (2014) The spleen and sickle cell disease: the sick(led) spleen. Br J Haematol 166(2):165-176. https://doi.org/10.1111/bjh.12950

2. de Back DZ, Kostova EB, van Kraaij M, van den Berg TK, van Bruggen R (2014) Of macrophages and red blood cells; a complex love story. Front Physiol 5. https://doi.org/10.3389/fphys.2014.00009

3. Bosman G, Willekens F, Werre J (2005) Erythrocyte aging: a more than superficial resemblance to apoptosis? Cell Physiol Biochem 16(1-3):1-8. https://doi.org/10.1159/000087725

4. Qadri SM, Bissinger R, Solh Z, Oldenborg P-A (2017) Eryptosis in health and disease: a paradigm shift towards understanding the (patho)physiological implications of programmed cell death of erythrocytes. Blood Rev 31(6):349-361. https://doi.org/10.1016/j. blre.2017.06.001

5. Burger $\mathrm{P}$, Hilarius-Stokman $\mathrm{P}$, de Korte $\mathrm{D}$, van den Berg TK, van Bruggen R (2012) CD47 functions as a molecular switch for erythrocyte phagocytosis. Blood 119(23):5512-5521. https://doi.org/10. 1182/blood-2011-10-386805

6. Steevels TAM, Meyaard L (2011) Immune inhibitory receptors: essential regulators of phagocyte function. Eur J Immunol 41(3): 575-587. https://doi.org/10.1002/eji.201041179

7. Lv Z, Bian Z, Shi L, Niu S, Ha B, Tremblay A, Li L, Zhang X, Paluszynski J, Liu M, Zen K, Liu Y (2015) Loss of cell surface CD47 clustering formation and binding avidity to SIRP $\alpha$ facilitate apoptotic cell clearance by macrophages. J Immunol 195(2):661671. https://doi.org/10.4049/jimmunol.1401719

8. Oldenborg PA (2000) Role of CD47 as a marker of self on red blood cells. Science 288(5473):2051-2054. https://doi.org/10. 1126/science.288.5473.2051

9. Jaiswal S, Jamieson CHM, Pang WW, Park CY, Chao MP, Majeti $\mathrm{R}$, Traver D, van Rooijen N, Weissman IL (2009) CD47 is upregulated on circulating hematopoietic stem cells and leukemia cells to avoid phagocytosis. Cell 138(2):271-285. https://doi.org/10.1016/ j.cell.2009.05.046

10. Jiang P, Lagenaur CF, Narayanan V (1999) Integrin-associated protein is a ligand for the P84 neural adhesion molecule. J Biol Chem 274(2):559-562. https://doi.org/10.1074/jbc.274.2.559

11. Vernon-Wilson EF, Kee W-J, Willis AC, Barclay AN, Simmons DL, Brown MH (2000) CD47 is a ligand for rat macrophage membrane signal regulatory protein SIRP (OX41) and human $\operatorname{SIRP} \alpha 1$. Eur J Immunol 30(8):2130-2137. https://doi.org/10.1002/15214141(2000)30:8<2130::aid-immu2130>3.0.co;2-8

12. Oldenborg P-A (2013) CD47: a cell surface glycoprotein which regulates multiple functions of hematopoietic cells in health and disease. ISRN Hematology 2013:1-19. https://doi.org/10.1155/ 2013/614619

13. Pitanga TN, Vilas-Boas W, Cerqueira BAV, Seixas MO, Barbosa CG, Adorno EV, Goncalves MS (2013) Cytokine profiles in sickle cell anemia: pathways to be unraveled. Adv Biosci Biotechnol 04(07):6-12. https://doi.org/10.4236/abb.2013.47a1002

14. Kelsey JL, Whittemore AS, Evans AS, Thompson WD (1996) Methods in observational epidemiology. Monographs in Epidemiology and Biostatistics

15. Anniss AM, Sparrow RL (2002) Expression of CD47 (integrinassociated protein) decreases on red blood cells during storage. Transfus Apher Sci 27(3):233-238. https://doi.org/10.1016/s14730502(02)00070-8

16. Brightwell RM, Grzankowski KS, Lele S, Eng K, Arshad M, Chen $\mathrm{H}$, Odunsi K (2016) The CD47 "don't eat me signal" is highly expressed in human ovarian cancer. Gynecol Oncol 143(2):393397. https://doi.org/10.1016/j.ygyno.2016.08.325
17. Weiskopf $\mathrm{K}$ (2017) Cancer immunotherapy targeting the CD47/ SIRP $\alpha$ axis. Eur J Cancer 76:100-109. https://doi.org/10.1016/j. ejca.2017.02.013

18. Veillette A, Chen J (2018) SIRP $\alpha-C D 47$ immune checkpoint blockade in anticancer therapy. Trends Immunol 39(3):173-184. https://doi.org/10.1016/j.it.2017.12.005

19. Weiskopf K, Ring A, Garcia KC, Weissman I (2015) CD47blocking therapies stimulate macrophage cytokine secretion and are effective in a model of peritoneal carcinomatosis. Journal for ImmunoTherapy of Cancer 3(S2). https://doi.org/10.1186/20511426-3-s2-p248

20. Liu J, Wang L, Zhao F, Tseng S, Narayanan C, Shura L, Willingham S, Howard M, Prohaska S, Volkmer J, Chao M, Weissman IL, Majeti R (2015) Pre-clinical development of a humanized anti-CD47 antibody with anti-cancer therapeutic potential. PLoS One 10(9):e0137345. https://doi.org/10.1371/journal.pone.0137345

21. Petrova PS, Viller NN, Wong M, Pang X, Lin GH, Dodge K, Chai V, Chen H, Lee V, House V, Vigo NT, Jin D, Mutukura T, Charbonneau M, Truong T, Viau S, Johnson LD, Linderoth E, Sievers EL, Maleki Vareki S, Figueredo R, Pampillo M, Koropatnick J, Trudel S, Mbong $\mathrm{N}$, Jin L, Wang JC, Uger RA (2017) TTI-621 (SIRP $\alpha \mathrm{Fc})$ : a CD47blocking innate immune checkpoint inhibitor with broad antitumor activity and minimal erythrocyte binding. Clinical cancer research 23 (4):1068-1079. doi:https://doi.org/10.1158/1078-0432.Ccr-16-1700

22. Willingham SB, Volkmer JP, Gentles AJ, Sahoo D, Dalerba P, Mitra SS, Wang J, Contreras-Trujillo H, Martin R, Cohen JD, Lovelace P, Scheeren FA, Chao MP, Weiskopf K, Tang C, Volkmer AK, Naik TJ, Storm TA, Mosley AR, Edris B, Schmid SM, Sun CK, Chua MS, Murillo O, Rajendran P, Cha AC, Chin RK, Kim D, Adorno M, Raveh T, Tseng D, Jaiswal S, Enger P, Steinberg GK, Li G, So SK, Majeti R, Harsh GR, van de Rijn M, Teng NN, Sunwoo JB, Alizadeh AA, Clarke MF, Weissman IL (2012) The CD47-signal regulatory protein alpha (SIRPa) interaction is a therapeutic target for human solid tumors. Proc Natl Acad Sci U S A 109(17):6662-6667. https://doi.org/ 10.1073/pnas.1121623109

23. Velliquette RW, Aeschlimann J, Kirkegaard J, Shakarian G, Lomas-Francis C, Westhoff CM (2019) Monoclonal anti-CD47 interference in red cell and platelet testing. Transfusion 59(2): 730-737. https://doi.org/10.1111/trf.15033

24. Khandelwal S, van Rooijen N, Saxena RK (2007) Reduced expression of CD47 during murine red blood cell (RBC) senescence and its role in RBC clearance from the circulation. Transfusion 47(9): 1725-1732. https://doi.org/10.1111/j.1537-2995.2007.01348.x

25. Per-Arne O (2012) Role of CD47 and signal regulatory protein alpha $(\operatorname{SIRP} \alpha)$ in regulating the clearance of viable or aged blood cells. Transfus Med Hemother 39(5):315-320. https://doi.org/10. $1159 / 000342537$

26. Sosale NG, Rouhiparkouhi T, Bradshaw AM, Dimova R, Lipowsky R, Discher DE (2015) Cell rigidity and shape override CD47's "self"signaling in phagocytosis by hyperactivating myosin-II. Blood 125(3):542-552. https://doi.org/10.1182/blood-2014-06-585299

27. Hoppe CC (2014) Inflammatory mediators of endothelial injury in sickle cell disease. Hematol Oncol Clin North Am 28(2):265-286. https://doi.org/10.1016/j.hoc.2013.11.006

28. Tavakkoli F, Nahavandi M, Wyche MQ, Perlin E (2004) Plasma levels of TNF- $\alpha$ in sickle cell patients receiving hydroxyurea. Hematology 9(1):61-64. https://doi.org/10.1080/1024533032000158869

29. Qari MH, Dier U, Mousa SA (2012) Biomarkers of inflammation, growth factor, and coagulation activation in patients with sickle cell disease. Clin Appl Thromb Hemost 18(2):195-200. https://doi.org/ 10.1177/1076029611420992

30. Zhang D, Xu C, Manwani D, Frenette PS (2016) Neutrophils, platelets, and inflammatory pathways at the nexus of sickle cell disease pathophysiology. Blood 127(7):801-809. https://doi.org/10.1182/ blood-2015-09-618538 
31. Kohli DR, Li Y, Khasabov SG, Gupta P, Kehl LJ, Ericson ME, Nguyen J, Gupta V, Hebbel RP, Simone DA, Gupta K (2010) Painrelated behaviors and neurochemical alterations in mice expressing sickle hemoglobin: modulation by cannabinoids. Blood 116(3): 456-465. https://doi.org/10.1182/blood-2010-01-260372

32. Bosurgi L, Cao YG, Cabeza-Cabrerizo M, Tucci A, Hughes LD, Kong Y, Weinstein JS, Licona-Limon P, Schmid ET, Pelorosso F, Gagliani N, Craft JE, Flavell RA, Ghosh S, Rothlin CV (2017)
Macrophage function in tissue repair and remodeling requires IL4 or IL-13 with apoptotic cells. Science 356(6342):1072-1076. https://doi.org/10.1126/science.aai8132

Publisher's note Springer Nature remains neutral with regard to jurisdictional claims in published maps and institutional affiliations. 